\title{
BMJ Global Health Systematic review and meta-analysis of the adolescent HIV continuum of care in South Africa: the Cresting Wave
}

\author{
Brian C Zanoni, ${ }^{1,2}$ Moherndran Archary, ${ }^{3,4}$ Sarah Buchan, ${ }^{5}$ Ingrid T Katz, ${ }^{1,2,6}$ \\ Jessica E Haberer ${ }^{1,2}$
}

To cite: Zanoni BC,

Archary M, Buchan S, et al. Systematic review and metaanalysis of the adolescent HIV continuum of care in South Africa: the Cresting Wave. BMJ Global Health 2016;1:e00004.

doi:10.1136/bmjgh-2015000004

Received 29 0ctober 2015 Revised 23 June 2016 Accepted 8 August 2016

CrossMark

\footnotetext{
${ }^{1}$ Massachusetts General Hospital, Boston,

Massachusetts, USA

${ }^{2}$ Harvard Medical School, Boston, Massachusetts, USA ${ }^{3}$ University of KwaZulu-Natal Nelson Mandela School of Medicine, Durban, South Africa

${ }^{4}$ Department of Pediatrics, King Edward Hospital, Durban, South Africa

${ }^{5}$ Dalla Lana School of Public Health, University of Toronto, Toronto, Ontario, Canada ${ }^{6}$ Brigham and Women's Hospital, Boston, Massachusetts, USA
}

Correspondence to Dr Brian C Zanoni; bzanoni@mgh.harvard.edu

\section{ABSTRACT}

Context: South Africa has the most HIV infections of any country in the world, yet little is known about the adolescent continuum of care from HIV diagnosis through viral suppression.

Objective: To determine the adolescent HIV continuum of care in South Africa.

Data sources: We searched PubMed, Google Scholar and online conference proceedings from International AIDS Society (IAS), International AIDS Conference (AIDS) and Conference on Retrovirology and Opportunistic Infections (CROI) from 1 January 2005 to 31 July 2015.

Data extraction: We selected published literature containing South African cohorts and epidemiological data reporting primary data for youth (15-24 years of age) at any stage of the HIV continuum of care (ie, diagnosis, treatment, retention, viral suppression). For the meta-analysis we used six sources for retention in care and nine for viral suppression.

Results: Among the estimated 867283 HIV-infected youth from 15 to 24 years old in South Africa in 2013, $14 \%$ accessed antiretroviral therapy (ART). Of those on therapy, $\sim 83 \%$ were retained in care and $81 \%$ were virally suppressed. Overall, we estimate that $10 \%$ of HIV-infected youth in South Africa in 2013 were virally suppressed.

Limitations: This analysis relies on published data from large mostly urban South Africa cohorts limiting the generalisability to all adolescents.

Conclusions: Despite a large increase in ART programmes in South Africa that have relatively high retention rates and viral suppression rates among HIVinfected youth, only a small percentage are virally suppressed, largely due to low numbers of adolescents and young adults accessing ART.

\section{INTRODUCTION}

South Africa has the highest number of HIV infections of any country in the world with an estimated 6.8 million total infections. ${ }^{1}$ Access to antiretroviral therapy (ART) did not begin until 2004, a delay that contributed to high numbers of perinatal HIV infections in the late 1990s and early 2000s. ${ }^{2}$ Even

\section{Key questions}

What is already known about this topic?

- The incidence of HIV infection among adolescents and young adults in South Africa is high.

- Perinatally HIV-infected children are ageing to adolescence and young adulthood.

- Adolescents and young adults have lower retention in care and lower viral suppression rates than older adults.

What are the new findings?

- There are an estimated 720000 HIV-infected youth aged 15-24 in South Africa.

- Overall $10 \%$ of HIV-infected youth in South Africa are virally suppressed.

- Among the estimated 867283 HIV-infected youth aged 15-24 years in South Africa in 2013, $14 \%$ accessed antiretroviral therapy (ART).

- Of those on therapy, approximately $83 \%$ were retained in care and $81 \%$ were virally suppressed.

\section{Recommendations for policy}

- Increasing antiretroviral treatment in adolescents and young adults.

- Improving adolescent-friendly services to increase retention and viral suppression rates.

- Preparation and planning for transition care for HIV-infected youth.

with the implementation of the South African National Antiretroviral Treatment Programme, enrolment was slow due to political, cultural, infrastructure, geographic and economic issues. ${ }^{3}{ }^{4}$ Many perinatally HIV-infected infants died during the delays in ART rollout. ${ }^{35}$

With improved access to ART, perinatally HIV-infected infants are surviving into adolescence and early adulthood. ${ }^{2}$ At the same time, adolescents and young adults, particularly females aged 15-24, have a high incidence of new HIV infections. ${ }^{6}$ These two groups, perinatally infected and non-perinatally infected adolescents and young adults, make up a 
significant portion $(11 \%)$ of South Africa's total number of HIV infections.

Now, with more than 10 years of an established national ART programme and its increased scale up in recent years, South Africa has the largest national ART programme in the world. ${ }^{2} 7$ Backed by emerging evidence, national ART guidelines support earlier initiation of ART with simpler, more potent and less toxic regimens leading to increased numbers of individuals accessing treatment. ${ }^{8}$ The scale-up has contributed to high levels of viral suppression, lower mortality rates and decreased HIV transmission among large adult populations in South Africa. ${ }^{29-11}$

Several groups have evaluated the continuum of HIV care (from HIV infection to diagnosis, linkage to care, retention in care, ART initiation and viral suppression) in adults from resource-rich countries. Analyses indicate that only a small number of HIV-infected individuals are fully benefitting from therapy. ${ }^{2}{ }^{12-14}$ In sub-Saharan Africa, $\sim 24 \%$ of HIV-infected individuals successfully navigate the continuum of care and are virally suppressed. ${ }^{2}$ An analysis of the adolescent and young adult continuum of care in the USA estimated that only $6 \%$ of HIV-infected youth were virally suppressed. ${ }^{13}$ The continuum of care for HIV-infected adolescents and young adults in South Africa has not previously been described.

The purpose of this analysis is to assess the number perinatally and non-perinatally HIV-infected adolescents requiring ART and surviving into adulthood. Preparing for this growing population has major implications for South Africa's national treatment programme, including the need for adolescent-friendly HIV prevention and treatment programmes as well as transition to adult services for HIV-infected youth.

Below, we present the results of a systematic review estimating the number of adolescents and young adults infected with HIV in South Africa, the number of those on ART and HIV-related mortality. In addition, we report results from our meta-analysis on the percentage of HIV-infected adolescents in South Africa who are retained in care and virally suppressed.

\section{METHODS}

We searched PubMed, Google Scholar and online conference proceedings from the International AIDS Society (IAS), the International AIDS Conference (AIDS) and the Conference on Retrovirology and Opportunistic Infections (CROI) from 1 January 2005 to 31 July 2015. Key words and medical subject headings relevant to age (ie, adolescent, adolescence, teen, youth, young adults) were cross-referenced with terms associated with the HIV continuum of care (ie, retention, loss to follow-up, viral suppression, ART, virological failure, outcomes and transition). We sought unpublished data from the South African Department of Health and major academic centres in Johannesburg, Durban, Pietermaritzburg and Cape Town. We reviewed literature in English reporting primary observational data from South African cohorts or epidemiological studies that included specific age ranges, including adolescents and young adults within our target age group of 15-24 years. We attempted to contact the corresponding authors of studies that included ages outside of this range. Because studies reported variable age ranges, we included studies in our analysis that reported primary data on youth, including the ranges of 15-24 years. We report age ranges as described by the original authors; therefore, this analysis includes adolescents and young adults as young as 9 years old and as old as 29 years old due to different binning of age groups by original authors.

We used epidemiological data from South African HIV antenatal HIV prevalence rates, reported number of live births and estimated mother-to-child HIV transmission rates to estimate the annual number of HIV-infected infants born each year in South Africa.

In our meta-analysis, we calculated pooled proportions, with corresponding 95\% CIs, for retention in care and viral suppression using the DerSimonian and Laird Random Effects (RE) model, with double arcsine transformation to stabilise the variance. ${ }^{15}{ }^{16}$ Meta-analyses were performed in MetaXL (V.3.1, EpiGear International, Queensland, Australia) (Barendregt JD, Doi SA. MetaXL User Guide. 2015;Version 3.1). Heterogeneity was assessed with the $\mathrm{I}^{2}$ statistic. $^{17}$ We planned analyses by relevant subgroups, focusing on age groups and study endpoints, to examine anticipated variation in the outcomes of interest.

\section{Findings}

Our systematic review found 119 relevant articles in the published literature addressing the continuum of care for HIV-infected adolescents in South Africa. As indicated in figure 1,78 were excluded due to insufficient primary data reported; 15 were excluded since they contained only adult data; eight were excluded for only including paediatric data (with ages $<15$ years); seven were excluded since they reported cohorts outside of South Africa and an additional four were excluded since they did not report results for the ages 15-24 in the primary outcomes. We searched 1266 conference abstracts from IAS/AIDS and CROI from 1 January 2005 to 31 July 2015 and found 12 that included primary data from South African cohorts involving adolescent retention or viral suppression. Six of these studies were excluded for insufficient primary outcome data. Overall, there were 13 sources that contained sufficient data to be included in the meta-analysis with two studies containing both retention and viral suppression data.

\section{Systematic review}

Overview of HIV Infections among Adolescents and Young Adults in South Africa.

Currently, HIV-infected adolescents and young adults in South Africa are a combination of two separate epidemics, perinatally HIV-infected youth and newly 


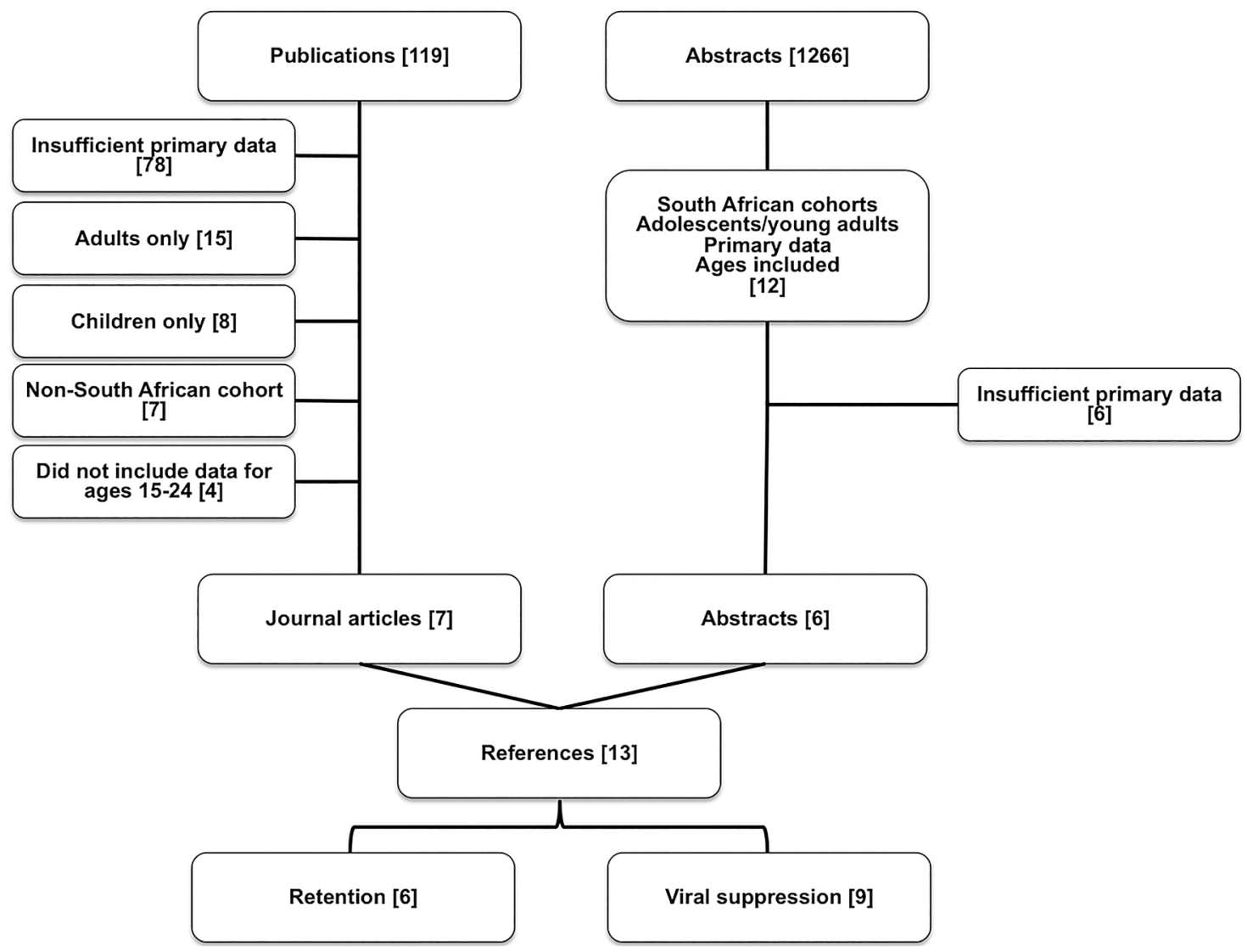

Figure 1 Flow diagram of literature reviewed for meta-analysis of retention in care and viral suppression for HIV-infected adolescents and young adults in South Africa published or presented between 1 January 2005 and 31 July 2015.

acquired HIV among adolescents and young adults. The South African National HIV Prevalence, Incidence, and Behavior Survey in 2012 estimated that up to a total of 720000 youth aged 15-24 are infected with HIV. ${ }^{6}$ By 2013 statistics, South Africa estimated that $8.5 \%$ of the estimated 10203329 adolescents and young adults aged 15-24 were infected with HIV totalling 867283 infections. ${ }^{18}$ Joint United Nations Programme on HIV/AIDS (UNAIDS) estimated there were 320000 HIV-infected adolescents aged 10-19 in 2013. ${ }^{19}$ These estimates contain both perinatally infected and non-perinatally infected youth; however, they do not extrapolate on the percentages in each category.

\section{Perinatal infections}

In 2003, before the implementation of the South African National HIV Treatment Programme, national HIV prevalence among women attending antenatal clinics was $27.9 \%$; yet, the number of pregnant women who tested for HIV was $<50 \% .^{20}{ }^{21}$ Low testing rates and limited prevention of mother-to-child HIV transmission (PMTCT) services led to a mother-to-child HIV transmission rate of $23 \%$ in $2003 .^{22}$ With 1677415 infants born in South Africa in 2003, ${ }^{21}{ }^{23}$ this translates to 107639 newly HIV-infected infants. By 2005, after ART became available in South Africa, the national HIV antenatal clinic prevalence rate rose to $30.2 \%$, but the mother-to-child transmission rate decreased to $17 \%$. The 1380496 births in 2005 translated into 70875 newly HIV-infected infants. By 2012, the expansion of ART services and PMTCT, including updated PMTCT guidelines in 2008 and 2010, led to decreasing mother-to-child HIV transmission rates $(2.4 \%)$; however, with 1168403 births and a $29.5 \%$ antenatal clinic prevalence rate, this translated into 8272 newly HIV-infected infants. ${ }^{6} 72124$ The decline in infections from 2003 to 2012 represents a $92 \%$ reduction in new paediatric HIV infections in 9 years, as indicated in figure 2. ${ }^{67}$ Since the rollout of ART in South Africa, there has been a steady decrease in the mother-to-child transmission rate. UNAIDS estimated that in 2014 there were 65000 averted perinatal HIV infections by PMTCT in South Africa. ${ }^{1}$

\section{Incidence of HIV among adolescents}

A national survey in 2012 estimated that 139000 new infections occurred among youth aged 15-24. ${ }^{6}$ The number of new infections disproportionally affects females who account for $81 \%$ of these new infections. ${ }^{6}$ The overall HIV incidence was 2.5 in females aged 15-24 compared with 0.6 for males of the same age. ${ }^{6}$

\section{Antiretroviral therapy}

In 2012, a nationally representative survey conducted in South Africa estimated 103000 (95\% CI 72000 to 
Figure 2 Systematic review: Perinatally HIV-infected infants in South Africa, total HIV-infected children aged 0-14 and the approaching wave of HIV-infected adolescents expected to enter adult care by 2023 .

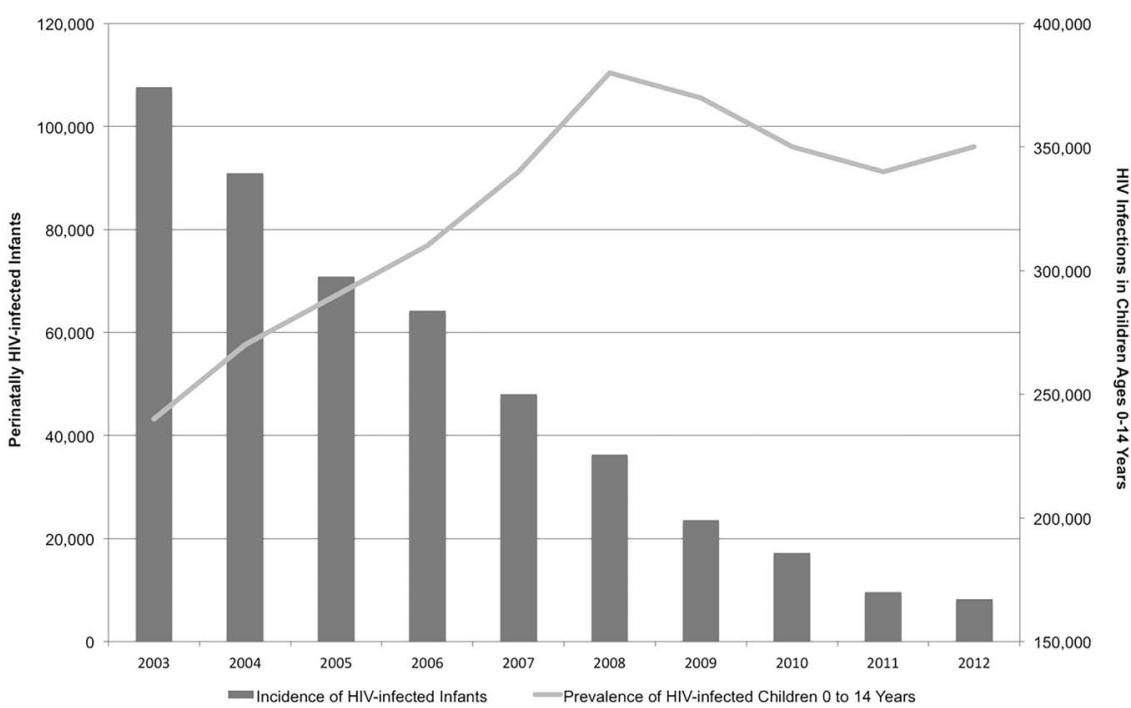

144000 ) youth aged 15-24 were on ART, comprising $14 \%$ of HIV-infected adolescents in South Africa and $1.5 \%$ of South Africans on ART. ${ }^{6}$ Estimates in large urban academic centres in Johannesburg, Cape Town and Durban have differing percentages of their total ART programme that are comprised of adolescents: Johannesburg at $6.7 \%$ for those aged 15-24; Cape Town at $0.8 \%$ for those $12-17$ and Durban $11.1 \%$ for those aged 10-19 (M Archary. KwaZulu-Natal Adolescent ART data. Personal Communication 2015; D Evans. Themba Lethu Clinic Adolescent Data. Personal Communication 2015; C Orrell. Masi and Gugulethu Adolescent Data. Personal Communication 2015). Based on 2013 population estimates, we estimate that 124070 (14\%; 95\% CI $10 \%$ to $20 \%$ ) adolescents and young adults aged $15-24$ in South Africa are receiving ART (figure 4).

\section{Meta-analysis}

Retention in care

Results of our meta-analysis of six studies estimate that the proportion of South African HIV-infected adolescents on ART who were retained in care within the first 1- 2 years of therapy is $83 \%$ (95\% CI $68 \%$ to $94 \%$; $\left.\mathrm{I}^{2}=99 \%\right)$, as indicated in table 1 and figures $3 \mathrm{~A}$ and $4 .^{25-30}$ No differences were seen when comparing this proportion by timing end point or age group.

\section{Viral suppression}

Based on our meta-analysis of eight studies, we estimate the proportion of South African adolescents and young adults on ART who were virally suppressed to be $81 \%$ ( $95 \%$ CI $74 \%$ to $87 \% ; \mathrm{I}^{2}=98 \%$ ), as indicated by table 1 and figures $3 \mathrm{~B}$ and $4 .^{26} 2829$ 36-39 41 No differences were seen when comparing this proportion by timing end point or age group.

\section{Mortality}

Globally, from 2005 to 2012, the overall number of HIV-related deaths decreased by $30 \%$; however, deaths in HIV-infected adolescents over the same time period increased by $50 \%{ }^{42}$ In 2013, in South Africa alone, there were more than 9500 deaths among HIV-infected adolescents. ${ }^{19}$ Despite having low ART initiation rates, lower retention in care and more virological failure, multiple cohorts in South Africa did not see an increase in mortality rates among adolescents and young adults in care and on ART. ${ }^{25} 26303643-48$

\section{DISCUSSION}

South Africa has had a dramatic increase in the number of HIV-infected individuals on ART in the last several years; however, the percentage of adolescents fully benefiting from treatment remains low. Compared with HIV-infected adolescents in the USA, South Africa has a lower percentage of youth receiving ART treatment ( $14 \%$ vs $25 \%$ ), yet it does have similar rates of retention in care $(11 \%$ vs $11 \%)$ and higher rates of viral suppression $(10 \%$ vs $6 \%) .{ }^{13} 49$ South Africa also has a higher number of infections at 867283 compared with 78949 in the USA. Despite a higher viral suppression rate, 709773 more adolescents are not virally suppressed in South Africa compared with the USA. Descriptions of the continuum of care for HIV-infected adolescents in others settings have not been described, limiting further comparisons.

South African studies with direct comparison between adolescents and adults indicate lower retention and viral suppression among youth. Six studies in South Africa documented significantly poorer retention in care rates for adolescents compared with adults with ORs ranging from 1.55 to 2.25. ${ }^{25} 2633343850$ For example, a large cohort from Gauteng and Mpumalanga with more than 42000 patients showed retention rates for adolescents aged 15-24 at 65\% compared with adults over 25 years of age at $78 \% .^{26}$ Five separate South African observational cohorts reported significantly lower HIV viral suppression rates among adolescents and young adults 
(range: 73-93\%) after ART initiation compared with adults (range: $88-97 \%$ ). ${ }^{26} 36385051$

Despite HIV-infected adolescents having lower rates of retention in care and viral suppression rates compared with adults, mortality rates among adolescents in comparative studies are similar to adults. ${ }^{25} \quad 26 \quad 30 \quad 36 \quad 43-48$ This likely reflects the delayed mortality in newly HIV-infected youth that die after ageing into adulthood. With high retention and viral suppression rates among adolescents in South Africa, strategies to improve HIV diagnosis and early ART initiation in adolescents could drastically improve the continuum of care for youth in South Africa.

Low ART treatment rates among adolescents currently are inversely related to the high number of new HIV infections in this age group. Youth who are newly infected are less likely to qualify for ART based on National HIV Treatment Guidelines (CD4 below 500 cells $/ \mathrm{mm}^{3}$ at the time of this writing) due to asymptomatic disease and higher CD4 counts. ${ }^{52}$ The cohort of sexually active, HIV-infected and viremic youth could have a large impact on HIV transmission rates in South

Table 1 Published literature from 1 January 2005 to 31 August 2015, addressing the continuum of care for HIV-infected adolescents and young adults in South Africa

\begin{tabular}{|c|c|c|c|c|c|}
\hline \multicolumn{6}{|l|}{ HIV infections } \\
\hline & Age & \multicolumn{2}{|l|}{ HIV infected } & \multicolumn{2}{|l|}{ Per cent } \\
\hline Shisana, $2014^{631}$ & $15-24$ & \multicolumn{2}{|l|}{720000} & \multicolumn{2}{|l|}{$7.1^{*}$} \\
\hline Statistics South Africa, $2013^{18}$ & $15-24$ & \multicolumn{2}{|l|}{867283} & \multicolumn{2}{|l|}{8.5} \\
\hline UNAIDS, $2013^{1819}$ & $10-19$ & \multicolumn{2}{|l|}{320000} & \multicolumn{2}{|l|}{$3.1 \dagger$} \\
\hline \multicolumn{6}{|l|}{ Antiretroviral therapy } \\
\hline & Age & HIV infected & On ART & \multicolumn{2}{|l|}{ Per cent } \\
\hline Shisana, $2014^{6}$ & $15-24$ & 720000 & 103000 & \multicolumn{2}{|l|}{14} \\
\hline \multicolumn{6}{|l|}{ Retention in care } \\
\hline & Age & $\mathrm{N}$ & Retained & Per cent & End point \\
\hline Maskew, $2012^{29}$ & $18-29$ & 1140 & 1018 & 89 & Retained 24 months \\
\hline Evans, $2013^{26}$ & $15-24$ & 1941 & 1252 & 65 & Retained 12 months \\
\hline Clouse, $2013^{25}$ & $18-29$ & 158 & 140 & 89 & Retained 12 months \\
\hline Peltzer, $2011^{30}$ & $18-28$ & 171 & 121 & 71 & Retained 12 months \\
\hline Fox, $2014^{32}$ & $18-29$ & 34 & 26 & 76 & Cross-sectional \\
\hline Laher, $2013^{28}$ & $9-26$ & 360 & 339 & 94 & Cross-sectional \\
\hline Boyles, $2011^{33}$ & Adults & \multicolumn{2}{|l|}{1803} & 82 & Cross-sectional \\
\hline Van Cutsem, $2010^{34}$ & Adults & \multicolumn{2}{|l|}{6411} & 92 & Cross-sectional \\
\hline \multirow{2}{*}{\multicolumn{2}{|c|}{ Meta-analysis of retention }} & $\mathrm{N}$ & Retained & \multicolumn{2}{|l|}{ Per cent } \\
\hline & & 3604 & 2896 & \multicolumn{2}{|c|}{$83 \%(95 \% \mathrm{Cl} 68 \%$ to $93 \%) ;\left.\right|^{2}=99 \%$} \\
\hline \multicolumn{6}{|l|}{ Viral suppression } \\
\hline & Age & $\mathrm{N}$ & Suppressed & Per cent & End pointł \\
\hline Evans, $2013^{26}$ & $15-24$ & 1941 & 1813 & 93 & 6 months \\
\hline Nglazi, $2012^{35}$ & $9-28$ & 472 & 343 & 73 & 6 months \\
\hline Mutevedzi, $2011^{36}$ & $16-24$ & 808 & 696 & 86 & 12 months \\
\hline Brittain, $2015^{37}$ & $9-14$ & 305 & 227 & 75 & Cross-sectional \\
\hline Van Cutsem, $2010^{38}$ & $10-24$ & 546 & 414 & 76 & 12 months \\
\hline Lazarus, $2010^{39}$ & $11-19$ & 107 & 90 & 84 & Cross-sectional \\
\hline Maskew, $2012^{29}$ & $18-29$ & 1738 & 1407 & 81 & 6 months \\
\hline Laher, $\mathbf{2 0 1 3 ^ { 2 8 }}$ & $9-26$ & 360 & 268 & 74 & Cross-sectional \\
\hline Davies, $2014^{\star 40}$ & $10-13$ & 2161 & 1664 & 77 & Cross-sectional \\
\hline \multirow{2}{*}{\multicolumn{2}{|c|}{ Meta-analysis of viral suppression }} & $\mathrm{N}$ & Retained & \multicolumn{2}{|r|}{$81 \%(95 \% \mathrm{Cl} 74 \%$ to $87 \%) \cdot \mathrm{I}^{2}=98 \%$} \\
\hline & & 6227 & 5258 & & $81 \%(95 \% \mathrm{Cl} 74 \%$ to $87 \%) ; \mathrm{I}^{2}=98 \%$ \\
\hline
\end{tabular}

Bolded citations were included in meta-analysis.

${ }^{*}$ Calculated based on population data from 2012.

†Calculated based on population data from 2013.

$\ddagger$ Viral Suppression as Viral Load $<400$ copies $/ \mathrm{mL}$. 
Figure 3 (A) Meta-analysis retention: Forest plot of the proportion of HIV-infected adolescents and young adults in South Africa retained in care. (B) Meta-analysis viral suppression: Forest plot of the proportion of virally suppressed HIV-infected adolescents and young adults in South Africa.

Figure 4 Estimate of the absolute number of South African HIV-infected adolescents and young adults aged 15-24 completing the HIV continuum of care. investment.

Expansion of proven treatment and prevention programmes for adolescents and young adults could reduce

B

Africa and warrants consideration for public health
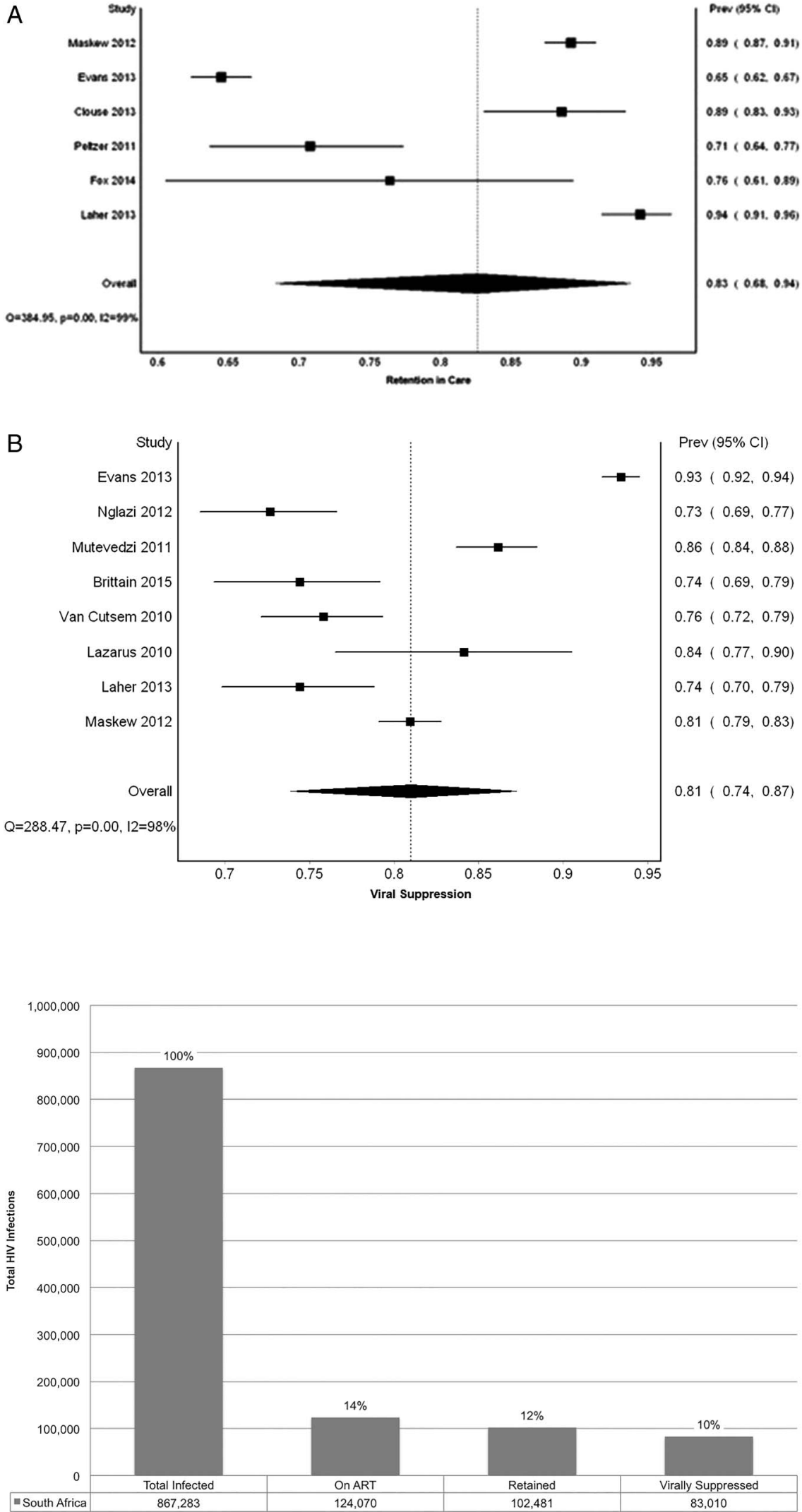
the high incidence of HIV infections in this age group. Recent evidence has shown the benefit of test-and-treat strategies for prevention of HIV regardless of clinical stage or absolute $\mathrm{CD} 4$, assuming individuals stay in 
care. ${ }^{53}$ Clinical evidence is also building for initiation of ART at higher CD4 counts. ${ }^{54}{ }^{55}$ Recently, the WHO recommended universal treatment for HIV-infected individuals, including adolescents and young adults. ${ }^{52} 5657$ In addition, pre-exposure prophylaxis, recently endorsed by the WHO, has been shown to decrease HIV transmission in several cohorts and may be useful in people engaging in high-risk sexual behaviour. ${ }^{57-60}$ However, concern about poor adherence among adolescents suggests that this strategy will require careful planning, monitoring and research.

The high HIV incidence rate among South African females aged 15-24 in particular calls for HIV prevention efforts in this group. Incidence rates for all other age groups have decreased over the past decade; however, incidence remains steadily high in females aged $15-24 .^{26}$ The risk of HIV acquisition among adolescent females is thought to be higher if there is a greater than 5-year difference in the age between female and male sexual partners. ${ }^{6}{ }^{61}$ Several studies suggest that this age discrepancy is driven by sexual relationships between older males and younger females as transactional sex. ${ }^{62-70}$ However, a recent study from rural KwaZulu-Natal, South Africa did not see an increase in HIV incidence among younger females with older male partners. ${ }^{71}$

There is an expected oncoming wave of perinatally HIV-infected children ageing into adolescence who will require adult services in the next 5-10 years. Infants surviving and initiating ART in the mid-2000s are now transitioning into adolescence. Additionally, $\sim 25-30 \%$ of perinatally infected children are slow progressors who can survive undiagnosed and untreated well into adolescence. ${ }^{72} 73$ As this wave of perinatally HIV-infected adolescents mature, combined with the high number of new infections among older adolescents, a large number of adolescents will transfer from paediatric or adolescentbased clinics to adult services. ${ }^{74-77}$ These already overwhelmed institutions are poorly prepared for the increased patient population. In addition, these individuals have different needs from patients currently in care at adult services. With many chronic illnesses, this transition is often associated with lapses in adherence and poor clinical outcomes. ${ }^{78-81}$ Revolving care providers, lack of youth-friendly services, rigid scheduling and decreased adult caregiver involvement have marred this transition process. ${ }^{82-84}$ More research is needed to investigate optimal practices for transitioning HIV-infected youth to adult services.

This review has several limitations. First, it relies on published data and therefore could be subject to publication bias, likely biasing adolescents to lower rates at each step of the continuum of care. We did, however, obtain estimates of the continuum of care from primary data from several large urban settings in Durban, Johannesburg, Pietermaritzburg and Cape Town. In addition, this review relied on retrospective observational data, which were mostly from large urban centres. It is possible that this data is not representative and generalisable to adolescents in rural settings. The analysis for viral suppression assumes that all participants in each cohort are alive, in care and do not have missing data. Since this was a retrospective review of the literature, we were unable to include clinical data such as CD4 improvement, weight gain and documentation of opportunistic infections. There was also considerable heterogeneity in the estimates for retention in care and viral suppression, which could not be explained by the variation in study endpoints or age group. Additional efforts are needed to try and explore the sources of this heterogeneity.

\section{CONCLUSION}

The oncoming wave of HIV-infected adolescents entering adult care could put a strain on already limited resources. These adolescents have different needs than adults and have lower viral suppression and retention rates. More research must be conducted to optimise retention in care, ART treatment and transition care for HIV-infected adolescents in South Africa.

\section{Handling editor Seye Abimbola}

Acknowledgements The authors would like to thank Thobekile Sibaya, Denise Evans and Catherine Orrell for assisting with data collection. They would also like to thank Holly Zanoni for her assistance with the figures and formatting.

Contributors BCZ conceptualised and designed the study, performed the literature review, assisted with the analysis, drafted the initial manuscript, reviewed and revised the manuscript and approved the final manuscript as submitted. SB and JEH carried out the initial analyses, reviewed and revised the manuscript and approved the final manuscript as submitted. MA and ITK provided information on data sources, method design and critically reviewed the manuscript and approved the final manuscript as submitted.

Funding $\mathrm{BCZ}$ is supported by the National Institute of Health (grant number 5T32Al 052074).

Competing interests None declared.

Provenance and peer review Not commissioned; externally peer reviewed.

Data sharing statement No additional data are available.

Open Access This is an Open Access article distributed in accordance with the Creative Commons Attribution Non Commercial (CC BY-NC 4.0) license, which permits others to distribute, remix, adapt, build upon this work noncommercially, and license their derivative works on different terms, provided the original work is properly cited and the use is non-commercial. See: http:// creativecommons.org/licenses/by-nc/4.0/

\section{REFERENCES}

1. Joint United Nations Programme on HIV/AIDS. UNAIDS Country Report: South Africa. 2015. http://www.unaids.org/en/ regionscountries/countries/southafrica

2. Joint United Nations Programme on HIV/AIDS. Global Report: UNAIDS Report on the Global AIDS Epidemic 2013. Joint United Nations Programme on HIV/AIDS, 2013. http://www.unaids.org

3. Chigwedere P, Seage GR III, Gruskin S, et al. Estimating the lost benefits of antiretroviral drug use in South Africa. J Acquir Immune Defic Syndr 2008;49:410-15.

4. Ojikutu B, Makadzange AT, Gaolathe T. Scaling up ART treatment capacity: lessons learned from South Africa, Zimbabwe, and Botswana. Curr Infect Dis Rep 2008;10:69-73.

5. Newell ML, Coovadia H, Cortina-Borja M, et al. Mortality of infected and uninfected infants born to HIV-infected mothers in Africa: a pooled analysis. Lancet 2004;364:1236-43. 
6. Shisana O, Rehle T, Simbayi LC, et al. South African National HIV Prevalence, Incidence and Behaviour Survey, 2012. Cape Town, HSRC Press, 2014, pp 57-60, 66-68.

7. Goga AE, Dinh TH, Jackson DJ, for the SAPMTCTE study group. Evaluation of the Effectiveness of the National Prevention of Motherto-Child Transmission (PMTCT) Programme Measured at Six Weeks Postpartum in South Africa, 2010. South African Medical Research Council, National Department of Health of South Africa and PEPFAR/US Centers for Disease Control and Prevention, 2012:2.

8. South African National Department of Health. National Consolidated Guidelines for the Prevention of Mother-to-child transmission of HIV (PMTCT) and the management of HIV in children, adolescents, and adults. Pretoria, South Africa: Department of Health, 2014.

9. Mossong J, Grapsa E, Tanser F, et al. Modelling HIV incidence and survival from age-specific seroprevalence after antiretroviral treatment scale-up in rural South Africa. AIDS 2013;27: 2471-9.

10. Zaba B, Marston M, Crampin AC, et al. Age-specific mortality patterns in HIV-infected individuals: a comparative analysis of African community study data. AIDS 2007;21(Suppl 6):S87-96.

11. Zaidi J, Grapsa E, Tanser F, et al. Dramatic increase in HIV prevalence after scale-up of antiretroviral treatment. AIDS 2013;27:2301-5.

12. Kilmarx PH, Mutasa-Apollo T. Patching a leaky pipe: the cascade of HIV care. Curr Opin HIV AIDS 2013;8:59-64.

13. Zanoni BC, Mayer $\mathrm{KH}$. The adolescent and young adult HIV cascade of care in the United States: exaggerated health disparities. AIDS Patient Care STDS 2014;28:128-35.

14. Gardner EM, McLees MP, Steiner JF, et al. The spectrum of engagement in HIV care and its relevance to test-and-treat strategies for prevention of HIV infection. Clin Infect Dis 2011;52:793-800.

15. Barendregt JJ, Doi SA, Lee YY, et al. Meta-analysis of prevalence. $J$ Epidemiol Community Health 2013:67:974-8.

16. DerSimonian R, Laird N. Meta-analysis in clinical trials. Control Clin Trials 1986;7:177-88.

17. Higgins JP, Thompson SG, Deeks JJ, et al. Measuring inconsistency in meta-analyses. BMJ 2003;327:557-60.

18. Statistics South Africa. Mid year population estimates: 2013. Pretoria, South Africa: Statistics South Africa; 2013. http://www. statssa.gov.za/publications/SAStatistics

19. The Joint United Nations Programme on HIV/AIDS (UNAIDS) HIV Estimates, 2013. http://allintoendadolescentaids.org/wp-content/ uploads/2015/02/South-Africa.pdf.

20. Joint United Nations Programme on HIV/AIDS. Republic of South Africa Country Progress Report on the Declaration of Commitment on HIV/AIDS 2010 Report. South African National Department of Health Health, 2010.

21. South African National Department of Health. The 2012 National Antenatal Sentinel HIV and Herpes Simplex type-2 prevalence Survey. Pretoria, South Africa: South African National Department of Health, 2012

22. Sherman GG, Lilian RR, Bhardwaj S, et al. Laboratory information system data demonstrate successful implementation of the prevention of mother-to-child transmission programme in South Africa. S Afr Med J 2014;104(Suppl 1):235-8.

23. Statistics South Africa. Recorded live births: 2013. Pretoria, South Africa: Statistics South Africa, 2013. http://www.statssa.gov.za/ publications/SAStatistics

24. Statistics South Africa (Stats SA). Recorded Live Births 2013. Statistical Release P0305. Page 9. http://www.statssa.gov.za/ publications/P0305/P03052013.pdf

25. Clouse $\mathrm{K}$, Pettifor AE, Maskew M, et al. Patient retention from HIV diagnosis through one year on antiretroviral therapy at a primary health care clinic in Johannesburg, South Africa. J Acquir Immune Defic Syndr 2013;62:e39-46.

26. Evans D, Menezes C, Mahomed K, et al. Treatment outcomes of HIV-infected adolescents attending public-sector HIV clinics across Gauteng and Mpumalanga, South Africa. AIDS Res Hum Retroviruses 2013;29:892-900.

27. Fox MP, Shearer K, Maskew M, et al. Treatment outcomes after 7 years of public-sector HIV treatment. AIDS 2012;26:1823-8.

28. Laher F, Hornschuh S, Otwombe K, et al. Outcomes of adolescents and young adults receiving antiretroviral therapy in Soweto, South Africa. Paper presented at: 7th IAS Conference on HIV Pathogenesis and Treatment Abstract no. MOPE0562013; Kuala Lumpur, Malaysia.

29. Maskew M, Brennan AT, MacPhail AP, et al. Poorer ART outcomes with increasing age at a large public sector HIV clinic in Johannesburg, South Africa. J Int Assoc Physicians AIDS Care (Chic) 2012;11:57-65.
30. Peltzer K, Ramlagan S, Khan MS, et al. The social and clinical characteristics of patients on antiretroviral therapy who are 'lost to follow-up' in KwaZulu-Natal, South Africa: a prospective study. SAHARA J 2011;8:179-86.

31. Statistics South Africa. South African Statistics 2012. Pretoria, South Africa: Statistics South Africa, 2012. http://www.statssa.gov.za/ publications/SAStatistics

32. Fox MP, Shearer K, Maskew M, et al. Attrition through multiple stages of pre-treatment and ART HIV care in South Africa. PLOS ONE 2014;9:e110252.

33. Boyles TH, Wilkinson LS, Leisegang R, et al. Factors influencing retention in care after starting antiretroviral therapy in a rural South African programme. PLOS ONE 2011;6:e19201.

34. Van Cutsem G, Ford N, Hildebrand K, et al. Correcting for mortality among patients lost to follow up on antiretroviral therapy in South Africa: a cohort analysis. PLoS ONE 2011;6:e14684.

35. Nglazi MD, Kranzer K, Holele P, et al. Treatment outcomes in HIV-infected adolescents attending a community-based antiretroviral therapy clinic in South Africa. BMC Infect Dis 2012;12:21.

36. Mutevedzi PC, Lessells RJ, Rodger AJ, et al. Association of age with mortality and virological and immunological response to antiretroviral therapy in rural South African adults. PLOS ONE 2011;6:e21795.

37. Brittain KA-A, N.A, Hoare J, Bekker, L-G, Nuttall J., Roux P, Stein D.J, Zar H.J, Myer L. Antiretroviral therapy adherence in perinatally-infected adolescents in Cape Town, South Africa. Paper presented at: International AIDS Society (IAS) Abstract no. MOPEB2032015; Vancouver, CA.

38. Van Cutsem G KL, Abrahams M, Kerschberger B, et al. Outcomes in children, adolescent, youth and adults on ART in Khayelitsha. Paper presented at: AIDS 2010-XVIII International AIDS Conference Abstract no. THPE0170; Vienna, 2010.

39. Lazarus EM OK, Mohapi L, Cescon A, et al. Effect of baseline immunological condition, virological response and duration of HAART on growth in HIV-infected adolescents. Paper presented at: XVIII International AIDS Conference: Abstract no. MOAB04032010; Vienna.

40. Davies M-A SK, Technau K, Phiri S, et al. Outcomes of Perinatally HIV-infected Adolescents on Antiretroviral Therapy in Southern Africa. Paper presented at: Conference on Retrovirology and Opportunistic Infections (CROI) Abstract no: 9302014; Boston, MA.

41. Davies MA, May M, Bolton-Moore C, et al. Prognosis of children with HIV-1 infection starting antiretroviral therapy in Southern Africa: a collaborative analysis of treatment programs. Pediatr Infect Dis $J$ 2014:33:608-16.

42. World Health Orginization. HIV and adolescents: guidance for HIV testing and counselling and care for adolescents living with HIV. Geneva, Switzerland: World Health Organization, 2013.

43. Ahonkhai AA, Noubary F, Munro A, et al. Not all are lost: interrupted laboratory monitoring, early death, and loss to follow-up (LTFU) in a large South African treatment program. PLOS ONE 2012;7:e32993.

44. Davies MA, Keiser O, Technau K, et al. Outcomes of the South African National Antiretroviral Treatment Programme for children: the leDEA Southern Africa collaboration. S Afr Med J 2009;99:730-7.

45. Fatti G, Meintjes G, Shea J, et al. Improved survival and antiretroviral treatment outcomes in adults receiving community-based adherence support: 5-year results from a multicentre cohort study in South Africa. J Acquir Immune Defic Syndr 2012;61:e50-8.

46. Hoffmann CJ, Fielding KL, Johnston V, et al. Changing predictors of mortality over time from cART start: implications for care. J Acquir Immune Defic Syndr 2011;58:269-76.

47. MacPherson P, Moshabela M, Martinson N, et al. Mortality and loss to follow-up among HAART initiators in rural South Africa. Trans $R$ Soc Trop Med Hyg 2009;103:588-93.

48. Vella V, Govender T, Dlamini S, et al. Retrospective study on the critical factors for retaining patients on antiretroviral therapy in KwaZulu-Natal, South Africa. J Acquir Immune Defic Syndr 2010;55:109-16.

49. Kapogiannis B XJ, Mayer K, Loeb J, et al. and the ATN/SMILE Collaborative. The HIV continuum of care for adolescents and young adults (12-24 years) attending 13 urban Us centers of the NICHD-ATN-CDC-HRSA SMILE collaborative. Paper presented at: 8th IAS Conference on HIV Pathogenesis, Treatment and Prevention2015; Vancover.

50. Nglazi MD, Lawn SD, Kaplan R, et al. Changes in programmatic outcomes during 7 years of scale-up at a community-based antiretroviral treatment service in South Africa. J Acquir Immune Defic Syndr 2011;56:e1-8.

51. Barth RE, van der Meer JT, Hoepelman Al, et al. Effectiveness of highly active antiretroviral therapy administered by general 
practitioners in rural South Africa. Eur J Clin Microbiol Infect Dis 2008;27:977-84.

52. Panel on Antiretroviral Guidelines for Adults and Adolescents. Guidelines for the use of antiretroviral agents in HIV-1-infected adults and adolescents. In: Services. Department of Health and Human Services. http://www.aidsinfo.nih.gov/ContentFiles/ AdultandAdoles2015

53. Cohen MS, Chen YQ, McCauley M, et al. Prevention of HIV-1 infection with early antiretroviral therapy. $N$ Engl J Med 2011;365:493-505.

54. Lundgren JD, Babiker AG, Gordin F, et al., INSIGHT START Study Group. Initiation of antiretroviral therapy in early asymptomatic HIV infection. N Engl J Med 2015;373:795-807.

55. Temprano ANS, Study G, Danel C, et al. A trial of early antiretrovirals and isoniazid preventive therapy in Africa. $N$ Engl J Med 2015;373:808-22.

56. World Health Organization. Consolidated guidelines on the use of antiretroviral drugs for treating and preventing HIV infection. Geneva, Switzerland: WHO, 2013

57. World Health Organization. Guideline on when to start antiretroviral therapy and on pre-exposure prophylaxis for HIV. Geneva, Switzerland: World Health Organization, 2015

58. Molina JCC, Spire B, vPialoux G, et al. On Demand PrEP With Oral TDF-FTC in MSM: Results of the ANRS Ipergay Trial: Abstract 23LB. Conference on Retrovirology and Opportunistic Infections (CROI); Seattle, WA, 2015.

59. Grant RM, Lama JR, Anderson PL, et al. Preexposure chemoprophylaxis for HIV prevention in men who have sex with men. N Engl J Med 2010;363:2587-99.

60. Baeten JM, Donnell D, Ndase P, et al. Antiretroviral prophylaxis for HIV prevention in heterosexual men and women. $N$ Engl J Med 2012;367:399-410.

61. Ott MQ, Barnighausen T, Tanser F, et al. Age-gaps in sexual partnerships: seeing beyond 'sugar daddies'. AIDS 2011;25:861-3.

62. Abdool Karim Q, Abdool Karim SS, Singh B, et al. Seroprevalence of HIV infection in rural South Africa. AIDS 1992;6:1535-9.

63. Anderson RM, May RM, Ng TW, et al. Age-dependent choice of sexual partners and the transmission dynamics of HIV in Sub-Saharan Africa. Philos Trans R Soc Lond B Biol Sci 1992;336:135-55.

64. Dunkle KL, Jewkes RK, Brown HC, et al. Transactional sex among women in Soweto, South Africa: prevalence, risk factors and association with HIV infection. Soc Sci Med 2004;59:1581-92.

65. Wojcicki JM. "She drank his money": survival sex and the problem of violence in taverns in Gauteng province, South Africa. Med Anthropol Q 2002;16:267-93.

66. Cluver L, Orkin M, Boyes $M$, et al. Transactional sex amongst AIDS-orphaned and AIDS-affected adolescents predicted by abuse and extreme poverty. J Acquir Immune Defic Syndr 2011;58:336-43.

67. Oldenburg CE, Perez-Brumer AG, Reisner SL, et al. Global burden of HIV among men who engage in transactional sex: a systematic review and meta-analysis. PLOS ONE 2014;9:e103549.

68. van der Heijden I, Swartz S. 'Something for something': the importance of talking about transactional sex with youth in South
Africa using a resilience-based approach. Afr J AIDS Res 2014;13:53-63

69. Watt MH, Aunon FM, Skinner D, et al. "Because he has bought for her, he wants to sleep with her": alcohol as a currency for sexual exchange in South African drinking venues. Soc Sci Med 2012;74:1005-12.

70. Zembe $Y Z$, Townsend L, Thorson A, et al. "Money talks, bullshit walks" interrogating notions of consumption and survival sex among young women engaging in transactional sex in post-apartheid South Africa: a qualitative enquiry. Global Health 2013;9:28.

71. Harling G, Newell ML, Tanser F, et al. Age-Disparate Relationships and HIV Incidence Amongst Rural South Africa Women. Paper presented at: Conference on Retrovirology and Opportunistic Infections (CROI) Abstract No. 1452014; Boston, MA.

72. Ferrand RA, Corbett EL, Wood R, et al. AIDS among older children and adolescents in Southern Africa: projecting the time course and magnitude of the epidemic. AIDS 2009;23:2039-46.

73. Marston $M$, Becquet $R$, Zaba $B$, et al. Net survival of perinatally and postnatally HIV-infected children: a pooled analysis of individual data from sub-Saharan Africa. Int J Epidemiol 2011;40:385-96.

74. Ikard K, Janney J, Hsu LC, et al. Estimation of unmet need for HIV primary medical care: a framework and three case studies. AIDS Educ Prev 2005;17(Suppl B):26-38.

75. Antiretroviral Therapy Cohort Collaboration. Life expectancy of individuals on combination antiretroviral therapy in high-income countries: a collaborative analysis of 14 cohort studies. Lancet 2008;372:293-9.

76. Committee On Pediatric Aids. Transitioning HIV-infected youth into adult health care. Pediatrics 2013;132:192-7.

77. Andiman WA. Transition from pediatric to adult healthcare services for young adults with chronic illnesses: the special case of human immunodeficiency virus infection. J Pediatr 2011;159:714-19.

78. Brousseau DC, Owens PL, Mosso AL, et al. Acute care utilization and rehospitalizations for sickle cell disease. JAMA 2010;303:1288-94.

79. Cervia JS. Easing the transition of HIV-infected adolescents to adult care. AIDS Patient Care STDS 2013;27:692-6.

80. Wiener LS, Kohrt BA, Battles HB, et al. The HIV experience: youth identified barriers for transitioning from pediatric to adult care. $J$ Pediatr Psychol 2011;36:141-54.

81. Fish R, Judd A, Jungmann $\mathrm{E}$, et al. Mortality in perinatally HIV-infected young people in England following transition to adult care: an HIV Young Persons Network (HYPNet) audit. HIV Med 2014;15:239-44.

82. Hunt SE, Sharma N. Transition from pediatric to adult care for patients with sickle cell disease. JAMA 2010;304:408-9; author reply 409.

83. Lowenthal ED, Marukutira T, Tshume O, et al. Parental absence from clinic predicts human immunodeficiency virus treatment failure in adolescents. JAMA Pediatr 2015;169:498-500.

84. Williams PL, Storm D, Montepiedra G, et al. Predictors of adherence to antiretroviral medications in children and adolescents with HIV infection. Pediatrics 2006;118:e1745-57. 